\title{
Knee septic arthritis caused by a-hemolytic Streptococcus in a patient with a recent history of knee arthroscopy: a case report
}

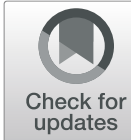

Giovanni Balato ${ }^{1 *}$, Tiziana Ascione 2 , Paolino lorio ${ }^{1}$, Cristiano De Franco ${ }^{1}$, Vincenzo De Matteo ${ }^{1}$, Alessio D’Addona', Nicola Tammaro ${ }^{3}$ and Achille Pellegrino ${ }^{4}$

\begin{abstract}
Background: Arthroscopic partial meniscectomy is a common procedure in orthopedic practice. Infections are uncommon complications of this procedure with an incidence rate of $0,01 \%-3,4 \%$. Staphylococcus spp are the predominant causative agents in such cases. We present a case of knee septic arthritis caused by a-hemolytic Streptococcus.

Case presentation: A 22-year-old woman diagnosed with obesity (body mass index [BMI] $35 \mathrm{~kg} / \mathrm{m}^{2}$ ) but with no other major comorbidities underwent an arthroscopic selective meniscectomy with administration of intravenous cefazolin for antibiotic prophylaxis. After an uneventful period of 2 months, the patient returned with pain, fever and a discharging sinus at the site of anterolateral arthroscopic portal. Blood tests and magnetic resonance imaging revealed osteomyelitis involving the tibial plate. Cultures of synovial fluid obtained from the knee and a pharyngeal swab yielded a-hemolytic Streptococcus. Five days later, the patient underwent arthroscopic debridement with partial synovectomy. Intraoperative specimens yielded a-hemolytic Streptococcus. The patient received intravenous piperacillin/tazobactam, followed by an associative regimen of amoxicillin and clindamycin with clinical, laboratory and instrumental evidence of symptom resolution.

Conclusion: The incidence of knee septic arthritis after arthroscopic partial meniscectomy is $0.01-3.4 \%$. This infection is usually caused by Staphylococcus spp. and in rare cases by commensal bacteria, such as a-hemolytic streptococci, secondary to transient bacteremia. Screening of the colonized area is important to prevent possible transient bacteremia. Diagnosis is based on isolation of the causative organisms from synovial fluid cultures, and treatment comprises arthroscopic debridement with individualized systemic antibiotic therapy based on the results of an antibiogram.
\end{abstract}

Keywords: Knee, Septic arthritis, Arthroscopic partial meniscectomy, Streptococcus spp

\section{Background}

Arthroscopic partial meniscectomy is one of the most common procedures in orthopedic practice. It is a reliable and cost-effective technique associated with good outcomes, low complication rates, and rapid recovery of function of the operated knee. Arthroscopy is performed for meniscal tears that cause pain and functional limitations. Outcomes of arthroscopic partial meniscectomy

\footnotetext{
* Correspondence: giovannibalato@gmail.com

${ }^{1}$ Unit of Orthopaedic Surgery, Department of Public Health, School of Medicine, Federico II University, Naples, Italy

Full list of author information is available at the end of the article
}

are affected by age, sex, type and location of meniscal tears, concomitant knee instability, and degenerative or traumatic articular lesions $[1,2]$.

Infections are uncommon complications of arthroscopy with an incidence rate of $0.01-3.4 \%$. Postsurgical septic arthritis is defined based on the following features: i) clinical presentation of fever, local pain, edema, erythema or tenderness; ii) laboratory investigations showing leukocytosis with elevated erythrocyte sedimentation rate (ESR), and C-reactive protein (CRP); iii) synovial fluid examination showing a white blood cell (WBC) count $>2.5 \times 10^{4} / \mu \mathrm{L}$ or positive synovial fluid culture results [3].

(c) The Author(s). 2019 Open Access This article is distributed under the terms of the Creative Commons Attribution 4.0 International License (http://creativecommons.org/licenses/by/4.0/), which permits unrestricted use, distribution, and reproduction in any medium, provided you give appropriate credit to the original author(s) and the source, provide a link to the Creative Commons license, and indicate if changes were made. The Creative Commons Public Domain Dedication waiver (http://creativecommons.org/publicdomain/zero/1.0/) applies to the data made available in this article, unless otherwise stated. 
Common risk factors for post-arthroscopic septic arthritis include open arthrotomy, procedure involving implants such as anterior cruciate ligament (ACL) allografts (which constitute foreign bodies), age $>50$ years and tourniquet time $>60$ min [4-6]. Staphylococcus aureus and Coagulase Negative Staphylococci are the most common causative agents, while Streptococci are involved with a lower frequency. The incidence of infections caused by $\alpha$ hemolytic Streptotoccus spp. is not described in the available literature, and limited anecdotal data are available from case reports [7, 8]. Streptococcus spp cause conjunctivitis, meningitis, bacterial pneumonia endocarditis, erysipelas and necrotizing fasciitis ("flesh-eating" bacterial infections), in addition to streptococcal pharyngitis [9].

Classification of Streptococcus spp is based on the hemolytic properties of these bacteria. Alpha-hemolytic species cause oxidization of iron in hemoglobin molecules within red blood cells, producing green-colored colonies on blood agar. Streptococcus pneumoniae and a group of oral streptococci (S. viridans) tipically cause alpha hemolysis [10].

We report a rare case of 22-year-old woman with obesity who developed septic arthritis secondary to $\alpha$ hemolytic streptococcal infection after simple arthroscopy.

\section{Case presentation}

Written informed consent for publication of their clinical details and/or clinical images was obtained from the patient. A copy of the consent form is available for review by the Editor of this journal.
A 22-years-old woman with obesity (BMI $35 \mathrm{~kg} / \mathrm{m}^{2}$ ) with no major comorbidities underwent arthroscopic selective lateral meniscectomy in March 2017. She received intravenously administered cefazolin $(2 \mathrm{~g})$ for antibiotic prophylaxis an hour before the skin incision, based on the protocol followed by our hospital and guidelines reported in the available literature [11]. Her postoperative recovery was uneventful until 2 months after the operation.

The patient was readmitted to the orthopedic department in May 2017 (8 weeks postoperatively) with pain, reduced mobility of the operated knee, and spiking fever > $38.5^{\circ} \mathrm{C}$. Physical examination on admission revealed a painful and edematous operated knee with a discharging sinus observed at the site of the anterolateral arthroscopic portal (Fig. 1). Laboratory examination revealed an elevated ESR $(55 \mathrm{~mm} / \mathrm{h})$ and serum CPR $(40 \mathrm{mg} / \mathrm{L})$. Blood and urine cultures were sterile. Magnetic resonance imaging (MRI) of the operated knee revealed evidence of septic arthritis with bone edema and abscesses surrounding surgical site (Fig. 2). Knee joint aspiration was performed for laboratory and microbiological investigations, which showed an elevated WBC count (54.000 cells/uL) with elevated levels of polymorphonuclear cells (93\%). Synovial fluid was cultured and yielded $\alpha$-hemolytic Streptococcus.

Pharyngeal swabs obtained on 2 consecutive days yielded the same $\alpha$-hemolytic Streptococcus, which were isolated earlier from aerobic cultures. It should be remembered that $\alpha$-hemolytic streptococci may be members of the normal oropharyngeal flora [12]. Transthoracic echocardiography

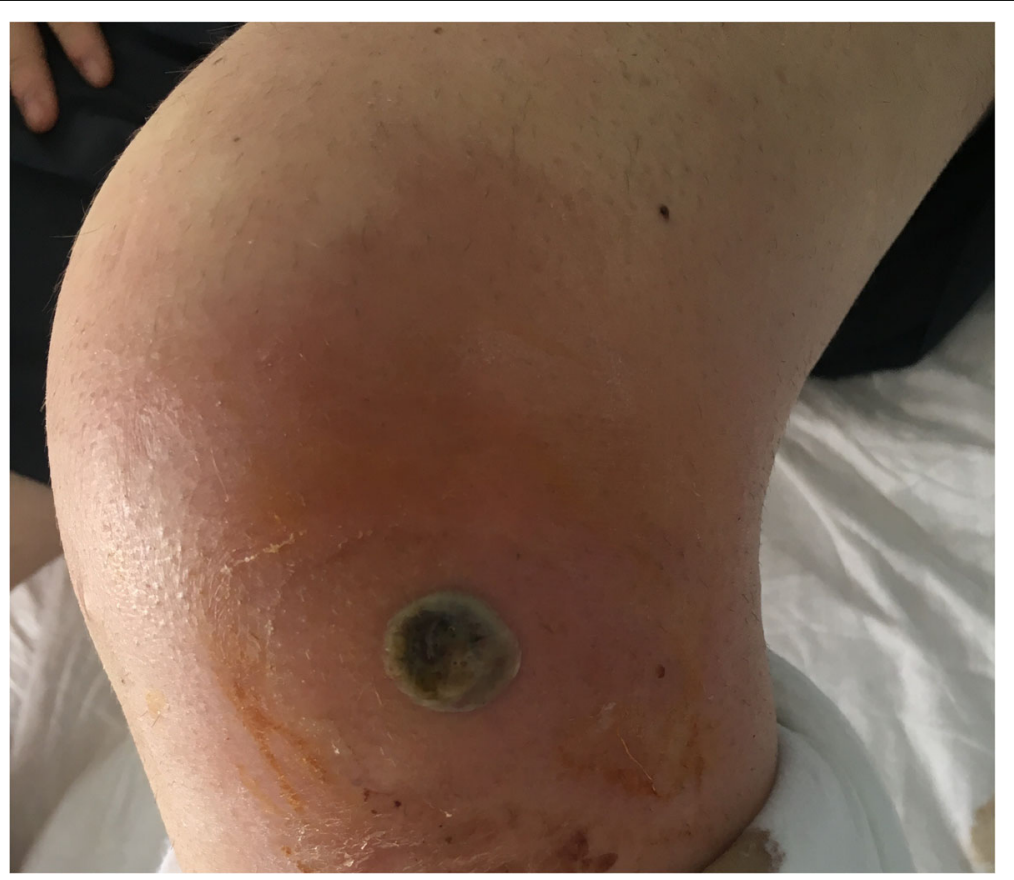

Fig. 1 Two months after the surgical procedure, the patient returned to control. In the post-operative period a fistula was observed on the site of the antero-lateral arthroscopic portal 


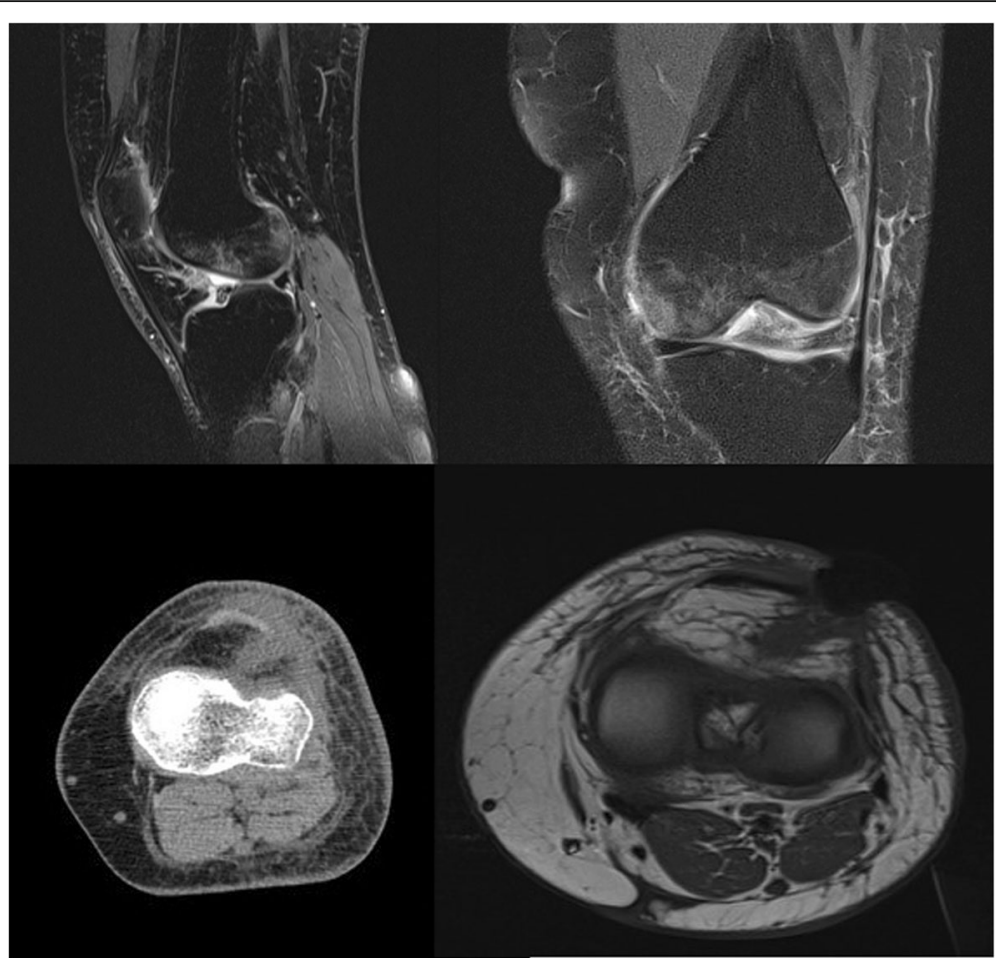

Fig. 2 The MRI study of the knee shows signs of septic arthritis, with bone edema and abscesses around surgical site and next to Hoffa. The presence of imbibition and swelling of the periarticular tissues (cutaneous and subcutaneous) can be observed

was performed to rule out possible bacterial endocarditis leading to haematogenous spread of infection to knee joint. However, this examination revealed no abnormalities.

Five days after the patient was readmitted to the orthopaedic department, arthroscopic debridement with partial synovectomy was performed, and teicoplanin $(8 \mathrm{mg} / \mathrm{kg}$ body weight) was administered daily while awaiting culture results to ensure adequate coverage for methicillin-resistant $S$. aureus, based on our hospital protocol. Cultures of intraoperative tissue samples confirmed the growth of $\alpha$ hemolytic Streptococcus susceptible to penicillin G, and the patient was administered piperacillin/tazobactam (13.5 g/ day) with rapid resolution of local signs and symptoms and improved serum CRP and ESR levels. Intravenous antibiotic therapy was continued for 2 weeks without significant adverse effects, based on the outpatient parenteral antibiotic therapy (OPAT) model. Two weeks after arthroscopic debridement, intravenous antibiotic therapy was switched to oral therapy with amoxicillin (1 $\mathrm{g}$ thrice daily) and clindamycin (150 mg twice a daily), for 8 weeks.

In July 2017 (8 weeks after debridement), ERS and CRP levels returned to the normal range with complete resolution of local signs of infection, and MRI revealed complete healing (Fig. 3).

In October 2017 ( 24 weeks after debridement), the patient did not show any evidence of infection. Functional evaluation revealed good results with complete range of motion (ROM), and the patient scored $100 / 100$ points each on Lysholm Knee Scoring Scale as well as Knee injury and Osteoarthritis Outcome Score (KOOS).

\section{Discussion and conclusions}

Knee arthroscopy is one of the most common procedures performed by orthopedic practice. According to the American Orthopaedic Surgery database from 2003 to 2009 , the overall complication associated with arthroscopic knee procedures was approximately $4.7 \%$.

Studies have shown that the overall complication rate associated with partial meniscectomies was approximately $2.8 \%$ and that infections constitute the most common complication (0.01-3.4\%) [13]. The incidence rate of infections requiring surgery after knee arthroscopy is approximately $0.15 \%$, with higher rates observed in men and in patients undergoing arthroscopies that require placement of implants [14].

Post-arthroscopic knee infections are more common in patients with obesity, smokers, patients undergoing complex procedures, men, patients with diabetes, and in procedures with time $>60$ min [15-18]. Surgical site infections (SSIs) are usually caused by commensals. Reports in the literature show that patient with $S$. aureus colonization in their nasal mucosa or skin are at a higher risk of SSIs. Several studies have reported an association between bacteria isolated from patients with SSI and 


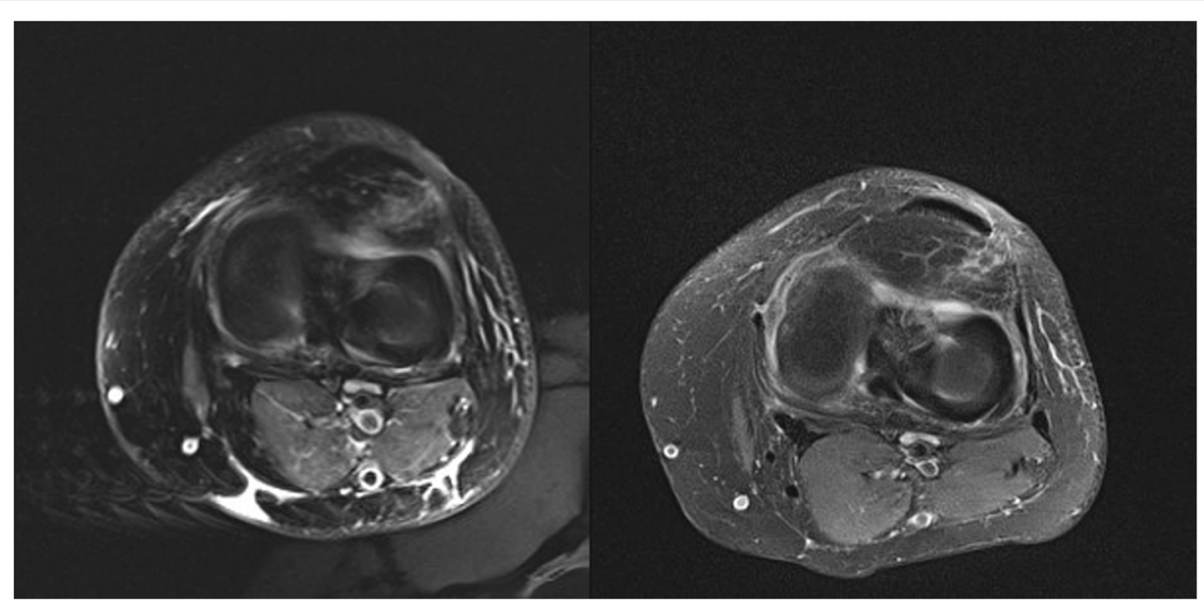

Fig. $3 \mathrm{MRl}$ after 30 (on the left) and 60 (on the right) days: the images show a reduction of imbibition and swelling of the periarticular tissues; besides the abscesses around the surgical site is not more detectable

their commensal flora [19-25]. Transient bacteremia from colonized site is associated with the theoretical risk of hematogenous spread of bacteria and seeding at the surgical site. Notably, $\alpha$-hemolytic streptococci are a large group of bacteria that are members of the oral commensal flora; however, in some cases, they can colonize distant organs (for example, in patients with diseases such as endocarditis [S. viridans]) [25]. To our knowledge, no report has described post-arthroscopic septic arthritis of the knee caused by $\alpha$-hemolytc streptococci, although staphylococcal joint infections are widely reported in the available literature [26-28]. We conclude that septic arthritis of the knee could be secondary to transient $\alpha$-hemolytic streptococcal bacteremia following seeding of oral flora at a site of recent surgery where necrotic tissue favors bacterial growth. Tobacco use, obesity, diabetes, age $>50$ years, and high-complexity procedures serve as risk factors for SSIs [28-31]. Diagnosis is based on culture examination of aspirated synovial fluid. Urgent therapeutic measures include copious arthroscopic irrigation and lavage, synovectomy, and concomitant administration of 2 effective antibiotics (based on the antibiogram) for at least 6 weeks [32]. Johns et al. [33] reported that outcomes of arthroscopic procedures were comparable with those of open surgery. Appropriate antibiotic therapy achieves effective eradication of infection in $85 \%$ of cases without any adverse effect on final function of the affected knee [34, 35].

Post-arthroscopic knee septic arthritis is a complication associated with significant morbidity. We report a rare case of post-arthroscopic septic knee arthritis in a young woman with obesity without any other risk factors predisposing to knee infection, including bacterial endocarditis that is known to cause hematogenous spread of infection to the knee. Septic arthritis of the knee is a serious complication of arthroscopy, which is usually caused by the Staphylococci spp. and by uncommon pathogenic bacteria in rare cases. We isolated $\alpha$-hemolytic Streptococcus following simple arthroscopy in our patient in whom the infection could be attributed to transient streptococcal bacteremia originating from the commensal oral flora of the patient. Therefore, we recommend screening the colonized area even in patients undergoing simple surgical procedures. Diagnosis in based on culture examination of aspirated synovial fluid. Arthroscopic debridement with administration of systemic antibiotics led to resolution of the infection in our patient.

\section{Abbreviations}

ACL: Anterior cruciate ligament; BMI: Body mass index; CRP: C-reactive protein; ESR: Erythrocyte sedimentation rate; KOOS: Knee injury and Osteoarthritis Outcome Score; MRI: Magnetic resonance imaging; PMN: Polymorphonuclear neutrophil; ROM: Range of motion; SSI: Surgical site infections; WBC: White blood cell

\section{Acknowledgements}

We thank Federico II University of Naples, Luigi Vanvitelli University of Naples and S.G. Moscati Hospital of Aversa (CE).

\section{Authors' contributions}

AP and NT collected the clinical data and designed the manuscript. TA and GB interpreted the clinical data. PI and AD wrote the manuscript. VdM and CDF revised the manuscript. All authors read and approved the final manuscript.

\section{Funding}

This report received no specific grant from any funding agency in the public, commercial or not-for-profit sectors.

\section{Availability of data and materials}

No datasets were generated or analysed during the current study. Data sharing is available from corresponding author on reasonable question.

Ethics approval and consent to participate Not applicable.

\section{Consent for publication}

Written informed consent was obtained from the patient described in this report. A copy of the written consent is available by request.

The authors declare that they have no competing interests. 


\section{Author details}

${ }^{1}$ Unit of Orthopaedic Surgery, Department of Public Health, School of Medicine, Federico II University, Naples, Italy. ${ }^{2}$ Department of Infectious Diseases, D. Cotugno Hospital, AORN Dei Colli, Naples, Italy. ${ }^{3}$ Department of Orthopedics, Traumatology, Plastic-Reconstructive and Rehabilitation, School of Medicine, Luigi Vanvitelli University, Naples, Italy. ${ }^{4}$ Unit of Orthopedics and Traumatology, S.G. Moscati Hospital, CE, Aversa, Italy.

Received: 11 January 2019 Accepted: 10 October 2019

Published online: 24 October 2019

\section{References}

1. Beaufils P, Pujol N. Management of traumatic meniscal tear and degenerative meniscal lesions. Save the meniscus. Orthop Traumatol Surg Res. 2017;103:S237-44.

2. Van de Graaf VA, Wolterbeek N, Mutsaerts EL, Scholtes VA, Saris DB, de Gast A, Poolman RW. Artrhoscopic partial Meniscectomy or conservative treatment for nonobstructive meniscal tears: a systematic review and metaanalysis of randomized controlled trials. Arthroscopy. 2016;32:1855-65.

3. Mathews CJ, Weston VC, Jones A, Field M, Coakley G. Bacterial septic arthritis in adults. Lancet. 2010;375:846-55.

4. Schuster P, Schulz M, Immendoerfer M, Mayer P, Schlumberger M, Richter J. Septic arthritis after arthroscopic anterior cruciate ligament reconstruction: evaluation of an arthroscopic graft-retaining treatment protocol. Am J Sports Med. 2015:43(12):3005-12.

5. Westermann R, Anthony CA, Duchman KR, Gao Y, Pugely AJ, Hettrich CM, Amendola N, Wolf BR. Infection following anterior cruciate ligament reconstruction: an analysis of 6,389 cases. J Knee Surg. 2017;30(6):535-43.

6. Murphy MV, Du DT, Hua W, Cortez KJ, Butler MG, Davis RL, DeCoster TA, Johnson L, Li L, Nakasato C, Nordin JD, Ramesh M, Schum M, Von Worley A, Zinderman C, Platt R, Klompas M. Risk factors for surgical site infections following anterior cruciate ligament reconstruction. Infect Control Hosp Epidemiol. 2016;37(7):827-33.

7. Good AE, Hague JM, Kauffman CA. Streptococcal endocarditis initially seen as septic arthritis. Arch Intern Med. 1978;138:805-6.

8. Reeves KD, Horvat RT. Aerosolized alpha-hemolytic Streptococcus as a cause of knee sepsis after intra-articular injection: predisposing factors. Am J Phys Med Rehabil. 2010;89:77-82.

9. van der Poll T, Opal SM. Pathogenesis, treatment, and prevention of pneumococcal pneumonia. Lancet. 2009;374(9700):1543-56.

10. Winslow C, Broadhurst J. The families and genera of the Bacteria: final report of the Committee of the Society of American bacteriologists on characterization and classification of bacterial types. J Bacteriol. 1920;1920(3):191-229.

11. Kurzweil PR. Antibiotic prophylaxis for arthroscopic surgery. Arthroscopy. 2006:22:452-4.

12. Aas JA, Paster BJ, Stokes LN, Olsen I, Dewhirst FE. Defining the normal bacterial flora of the oral cavity. J Clin Microbiol. 2005;43(11):5721-32.

13. Salzler MJ, Lin A, Miller CD, Herold S, Irrgang JJ, Harner CD. Complications after arthroscopic knee surgery. Am J Sports Med. 2014;42(2):292-6.

14. Yeranosian MG, Petrigliano FA, Terrell RD, Wang JC, McAllister DR. Incidence of postoperative infections requiring reoperation after arthroscopic knee surgery. Arthroscopy. 2013;29(8):1355-61.

15. Kinsella SD, Carey JL. Complications in brief: arthroscopic partial meniscectomy. Clin Orthop Real Res. 2013;471(5):1427-32.

16. Sing DC, Luan TF, Feeley BT, Zhang AL. Is obesity a risk factor for adverse events after knee arthroscopy? Arthroscopy. 2016;32(7):1346-53

17. Clement RC, Haddix KP, Creighton RA, Spang JT, Tennant JN, Kamath GV. Risk factors for infection after knee arthroscopy: analysis of 595,083 cases from 3 United States databases. Arthroscopy. 2016;32(12):2556-61.

18. Balato G, Di Donato SL, Ascione T, D'Addona A, Smeraglia F, Di Vico G, Rosa D. Knee septic arthritis after arthroscopy: incidence, risk factors, functional outcome, and infection eradication rate. Joints. 2017;5(2):107-13.

19. Bartz H, Cb N, Bollmann C, Kuhl M, Zimmermann S, Heeg K, et al. Micromonas (Peptostreptococcus) micros: unusual case of prosthetic joint infection associated with dental procedures. Int J Med Microbiol. 2005;294:465-70.

20. Bartzokas CA, Johnson R, Jane M, Martin MV, Pearce PK, Saw Y. Relation between mouth and haematogenous infection in total joint replacements. BMJ. 1994;309:506-8.

21. LaPorte DM, Waldman BJ, Mont MA, Hungerford DS. Infections associated with dental procedures in total hip arthroplasty. J Bone Joint Surg Br. 1999;81:56-9.
22. Quénard F, Seng P, Lagier JC, Fenollar F, Stein A. Prosthetic joint infection caused by Granulicatella adiacens: a case series and review of literature. BMC Musculoskelet Disord. 2017;18:276.

23. Rubin $R$, Salvati EA, Lewis $R$. Infected total hip replacement after dental procedures. Oral Surg Oral Med Oral Pathol. 1976;41:18-23.

24. Témoin S, Chakaki A, Askari A, El-Halaby A, Fitzgerald S, Marcus RE, et al. Identification of oral bacterial DNA in synovial fluid of patients with arthritis with native and failed prosthetic joints J Clin Rheumatol 2012: 18:117-121.

25. Bode $L G$, Kluytmans JA, Wertheim HF, et al. Preventing surgical-site infections in nasal carriers of Staphylococcus aureus. N Engl J Med. 2010;362:9-17.

26. Helito CP, Noffs GG, Pecora JR, Gobbi RG, Tirico LE, Lima AL, de Oliveira PR, Camanho GL. Epidemiology of septic arthritis of the knee at hospital das Clinicas, Universidade de Sao Paulo. Braz J Infect Dis. 2014;18:28-33.

27. Helito CP, Teixeira PR, Oliveira PR, Carvalho VC, Pécora JR, Camanho GL, Demange MK, Lima AL. Septic arthritis of the knee: clinical and laboratory comparison of groups with different etiologies. Clinics (Sao Paulo). 2016;71:715-9.

28. Cancienne JM, Gwathmey FW, Werner BC. Intraoperative corticosteroid injection at the time of KneeArthroscopy is associated with increased postoperative infection rates in a large Medicare population. Arthroscopy. 2016;32(1):90-5.

29. Qi Y, Yang X, Pan Z, Wang H, Chen L. Value of antibiotic prophylaxis in routine knee arthroscopy : a retrospective study. Orthopade. 2018;47(3):246-53.

30. Bert JM, Giannini D, Nace L. Antibiotic prophylaxis for arthroscopy of the knee: is it necessary? Arthroscopy. 2007;23(1):4-6.

31. Erdil M, Bilsel K, Sungur M, Dikmen G, Tuncer N, Polat G, Elmadag NM, Tuncay I, Asik M. Does obesity negatively affect the functional results of arthroscopic partial meniscectomy? A retrospective cohort study. Arthroscopy. 2013;29(2):232-7.

32. Ascione T, Balato G, Mariconda M, Rosa D, Rizzo M, Pagliano P. Postarthroscopic septic arthritis of the knee. Analysis of the outcome after treatment in a case series and systematic literature review. Eur Rev Med Pharmacol Sci. 2019;23:76-85.

33. Johns BP, Loewenthal MR, Dewar DC. Open compared with arthroscopic treatment of acute septic arthritis of the native knee. J Bone Joint Surg Am. 2017;99:499-505.

34. Bauer T, Boisrenoult P, Jenny JY. Post arthroscopy septic arthritis: current data and practical recommendations. Orthop Traumatol Surg Res. 2015; 101 (8 Suppl):S347-50.

35. Balato G, Ascione T, Rosa D, Pagliano P, Solarino G, Moretti B, Mariconda M. Release of gentamicin from cement spacers in two-stage procedures for hip and knee prosthetic infection: an in vivo pharmacokinetic study with clinical follow-up. J Biol Regul Homeost Agents. 2015;29(4 Suppl):63-72.

\section{Publisher's Note}

Springer Nature remains neutral with regard to jurisdictional claims in published maps and institutional affiliations.

Ready to submit your research? Choose BMC and benefit from:

- fast, convenient online submission

- thorough peer review by experienced researchers in your field

- rapid publication on acceptance

- support for research data, including large and complex data types

- gold Open Access which fosters wider collaboration and increased citations

- maximum visibility for your research: over $100 \mathrm{M}$ website views per year

At BMC, research is always in progress.

Learn more biomedcentral.com/submissions 